\title{
The Textural Criticism on the Intercultural Translation*
}

\begin{abstract}
WANG Ai-li
Bohai University, Jinzhou, China

Translation, being a bridge of bilingual and bi-cultural activities, has something concerned with thinking which is a part of culture. As different nations have various individuality, Intercultural Communication is the up-and-down field of translation where it is full of obstacles called "cultural shocks". Cultural misunderstandings from which mistranslation results are the main concerned problems in the thesis which the conspicuous cultural vacancy makes the translation the bottleneck when translating between source language and target one. In fact, in the process of Intercultural Communication, an appropriate translation should be a bi-cultural transferring with the bilingual translation through which the translator should be in the double-angled perspective between English and Chinese in which the meaning can be culturally right and misunderstanding will be avoided.
\end{abstract}

Keywords: bi-cultural transferring, bilingual translation, double-angled

\section{Introduction}

Language is a part of culture. Being a bilingual activity, translation is not only an activity across languages but also that of intercultural contact (HU, 2006, p. 268). Language and culture impact and balance each other. Being the product of culture, language has the conspicuous characteristics of culture. Whether people see it or not, from the semiotic perspective or the sociological one, it is the true culture. Culture which is the content of language gives the all-around impact on language. In this way, language is culture. The famous American linguist and translator Eugene A. Nida had ever argued that in the process of the real successful translation, even, it is more important for the translator to master bi-cultural knowledge than to master bilingual one, for words or verbal phrases will be meaningful in the cultural situation in which they will make sense. So, translation will be meaningful when the language, being with the cultural media, is concerned with the cultural contents. The translation hence should be a kind of cultural transferring or the cultural translation.

\section{Language Is the Cultural Heritage of a Society}

About culture, many anthropologists and linguists have defined it from various perspectives. The number of definitions of culture is estimated at least 150 kinds (HU, 1988, p. 4). Yet, it is rare that people regard language as culture. Culture in some sense orders or limits people's process of feeling the world and forming the concept of the world. In the end, people generate gradually the perceptual sets which are decided with culture eventually.

\footnotetext{
* The issued paper of The Training Class on Advanced Thesis Writing and Publication of the Mid-young Elite Teacher of English in the Center of Foreign Language Textbook and Teaching Methodology of Shanghai International Studies University entitled The Translation in the Perspective of Intercultural Communication.

WANG Ai-li, associate professor, M.A., School of Foreign Languages, Bohai University.
} 
Porter and samovar point out that "...Culture performs with the language pattern...” (HU, 2012, p. 33). Because language limits the way of people's thinking, language with thought is different between cultures. In fact, since language itself is culture. Different languages show different thoughts because of different cultures. Language comes from the animal's vocal grooming (GUI, 2012, p. 767) which is ahead of thinking. Because of the coming and null of the written language, it is not available to prove if people have their thinking or not. It is the monkey that strikes a hard nut with a stone that people argue whether monkey has the thought or not. The monkey fails the first time with eyes looking around feeling depressed. For the second time, he fails. The hard nut is rolling and slipping when striking. Seeing here and there from the corner of his eyes, he feels depressed again very much. For the third time, he makes it while laughing and going to show the happiness without looking around any longer but chewing again and again. If the situation is the same as people do, they will say "I made it" when breaking. If the best way fails to come out of his or her head, he will ask "what way is good?". Yet animals will only think in his mind and speak what people fail to understand simultaneously. For both people and monkey, it is good timing.

The way of thinking is decided with language. Apart from the distinction between language and speech, Saussure's another contribution to the world in linguistics is something synchronic and diachronic. It is of no necessity for people to argue that which is first, language or thinking. Thinking with language is coming into being simultaneously, yet the ruin is the invention of Chinese characters in the sense of Chinese. In fact, which is first to come into being will be proved. That will owe to the invention of loose leaf printing. No one knows what language and the way of thinking are. The invention of the both character and word is "the suspect" "who" kills the speaker while killing time to have built the Kingdom of linguistic language with langue which no body knows what it has ever been. In the opposite, language might be Father's uttering when his subjects are building the Babel Tower if there were such a tower.

The various nations own one world; the nature embodies the common sense in the various nations. It is this common sense that provides the feasible evidence of opportunities of communication for various nations and the feasible foundation to translate from one language to another (YANG, 2006, p. 306). The variation in different nations is the obstacle of the translation which is limited but surpassing. The father of the Intercultural Communication in China, Prof. Mr. HU Wen-zhong points out that culture embodies as the model of language, the form of activity and the style of people's behavior which are the sample of people's adjusting activities and appropriate behavior in the society. "The deposit" is the social relics. So language is the postnatal heritage of the society (HU, 2012, p. 34). It is the postnatal pragmatic rules mastered by people in the certain society that makes the world develop to the time being. Language is the style or sample to solve problems or issues emerging in people's daily life. Language is different as well because the culture is different. For example, "nigahane?" in Chinese pronunciation Jinzhou local accent meaning what are you doing has little to do with the Mandarin Chinese. Another example, suppose "zoushane?", Tianjin accent with the tone in the middle to end the utter which means "what are you doing?" is both bilingual and bi-cultural, if you call it sentence.

The author will ask: If these two utterances were spoken in the CCTV news in 19:00, how would the announcer announce? So if people say that it is language, that is language; for it is place of CCTV; if people say that it is culture, it is culture for it is spoken or uttered by people in the City of Jinzhou, Liaoning, China. Who can make it sure whether one situation of "What are you doing?" in Jinzhou local accent is the local uttering or the information decoding in CCTV? Maybe in certain place, time, two parties communicate with local accent: The 
male announcer would imitate with the Tianjin accent while one of the female person would speak in the Northeast of China imitating with Jinzhou accent. So Shakespeare's saying, the rose for another labeling proves the China rose for Rose. People call it rose for its love while some person call it China Rose for its infidelity. That is the deal: The Effect of Rose.

The various cultures result in different languages which cause the falling of Babel Tower not because the failure of the construction of Babel Tower but because, the Father, Jehovah who never asks his subjects to understand each other in the situation of the postnatal heritage of social culture. The first word of Bible with Chinese version taichuyouci is not an only word but the word of the Bible, the word of an utterance. Therefore, if people want to communicate with each other successfully, they have to invent a set of pragmatic rules in their communication and master them when uttering to manipulate the dialogue going on to find the solution to the problem. "Culture is the guidance of people's daily life" (HU, 2012, p. 34). The ICC happens when the deliverer of the information belongs to a certain culture, yet the receiver of the information is a member of another one.

The information encoded with one culture should be decoded with another one. After the information delivers, it leaves culture of encoding information with the expression of the encoding culture. The information received has been at least impacted with the decoding culture which has been inputting more or less the information of encoding culture. (XU, 2002, p. 47)

Yet is it arguable whether language is communication with parole face to face or is encoding and decoding in the situation of Internet? Translation is a necessary bridge and a medium in ICC which is both the semiotic switch and the linguistic transmutation. The eagerness is that the difficulties will emerge when covert semiotics converses into the cultural vacancy each other in homogeneous culture and heterogeneous one. So, the task of translator is to find the solution to the mistranslation as possibly as he/she can. He/she should pay much attention to not only the variation of ICC, but also interpreting the semantic culture to share the meaning culturally in communication.

\section{Mistranslations}

In the process of translation, the translator must inspect the usage of language in the social cultural communication to reach the social communicative equivalence. Simultaneously, the translation should focus on issues not only within the language, but also in different cultural backgrounds towards various languages. Halliday classifies sentence, parole, phrase, word, and morpheme concerning with English. Semantic expression is a kind of interaction within and out the languages which the parole is focused on. Here the parole is just what Widdowson stresses as the difference between the use and usage.

Chinese is a nation of modesty. So being modest in language is Chinese habit in writing and speaking. For example, in the title of Chinese thesis often "qiantan...", "shilun...", and "...tanwei" are written down. On the contrary, having read these titles, the English speaker argues that how can an article which is very shallow (qiantan) be published? or how can a writer convince readers if his/her credibility in writing is low (tanwei)? Actually, it is not simply the problem of language but the issue of culture (HU, 2006, p. 17). So the titles above should not be translated as "A preliminary talk/study on..." equivalently. If the meaning of the source language can be accepted and understood by the receiver of the target one when intercultural communication happens, the translation is easy and possible, however, if not, the cultural gap emerges, yet, the translation is difficult or 
impossible. Consequently, the translator will fail to get the social pragmatic equivalence. As for this, the solution to the wrong translation is to gain the bilingual and bi-cultural proficiency. Another example, "individualism" was translated as "gerenzhuyi" in Chinese. Because China is a collectivist country while America is an individualist one. The thoughts are quite different between two countries. The core of Individualism is the American spirit - initiative which people in that society should help himself or herself first then get help from God. The translator translates to the target language with the Chinese cultural context as "gerenzhuyi" which is sort of derogatory according to English. It is distorted with mistranslation. The right version should be "gexingzhuyi"/“getizhuyi" neutrally but not "gerenzhiyi" derogatorily. In fact, this is the obstacle of covert culture.

\section{The Communicative Trend}

The translation in China has experienced the phases of language, structural linguistics, and communication, which embody the translation with synchronicity and diachronicity. The traditional way of thinking is based on the subjectivity which is addicted to the unity. After the decision of the position of the structural linguistics, language forms the center of logos. In this way the clearness and the exactness are required, however, the trend of postmodernism wants to subvert the base of the subjectivity and eliminate the center of it. This trend is strong in destruction and stresses on the ambiguity and poly-elements. The interpreting philosophy and the theory of dialogue interpret that all the literary versions in translation are in a jumble (LV, 2002, p. 41). However, the functional translation theory states that the translating version with the function and aim of translation determines the strategy and methods in translation. The prediction of the translating version hence has to be manipulated by the rights of dialogue. So it is necessary for the translator to introduce Habermas' communicative moralities to the dealing with the relationship between the culture of source language and culture of target language in order to make the good recycle in intercultural communication and dialogues. Translation should make the dynamic interpretation and dig out the connotative meanings from the denotation of the source language because of the deep deposit in history and should dig out the etymological meaning...making each word of translation resemble in spirit and beautiful in language... (YANG, 2006, p. 78).

\section{The Cultural Transferring in Meaning}

Example: Shall I compare thee to a summer's day? / Thou art more lovely and more temperate:

Chinese version: nengbunengrangwolaibanibizuoxiari? / Nikeshigengjiakeai, gengjiawenwan? (HU, 2003, p. 36).

People living in Britain in the areas of high altitude like summer. Shakespeare regards the young handsome boy in his Sonnet 18 as summer which in England is mild and temperate because the wet west wind which is quite different from Chinese xifeng, is mild. It is the same as Chinese spring wind which is warm and mild when people are communicating each other they will mention it. This is because the different location geographically results in the cultural variation. The summer time in England is warm and full of moisture. It is the best season of the year. "The summer's day is temperate". So, "The eternal summer in English should be the same as mingmeidechuntian in Chinese" (WANG, 2004, p. 7), however, the summer in China is very hot. So the translator should not translate the summer as xiatian with the equivalent communication. This is a kind of 
bi-cultural vacancy in which the English summer does not exist in Chinese or Chinese chuntian does not exist in English. "So, the translator should choose the right season to translate in order to make the communicative equivalence in the target language" (YANG, 2006, p. 148). The "hot summer" is popular in Chinese, anyway, however, changing the "summer" into the "spring day" in the frame of cultural rewriting controlled by the manipulation theory is not the real translation but the fake one to the source English poem. The Chinese version

“...adopted little because of the lack of the adjustment from the context of the whole poem. In addition, making notes is rarely to be read in the famous collections of poetry" (WANG, 2004, p. 7).

Someone translates it as the wenwandexiari. If then, the contradiction emerges. Xiari in China is not the temperate day. It is hot. Another scholar in the field thinks that the image in the poem of the source language should be kept and should be rewritten, however, keeping the image of the source language in Chinese version is not fitful in Chinese language and culture. The key point lies in that the best season in England is summer for its mildness but the spring in China for its temperance. It is ambiguous for the translator to deal with in translation. Therefore, the translation which does not get rid of the cultural background could make the communicative equivalence. So, being the mediator of the culture, the translator should not simply carry the culture of the source language on his/her own authority. He or she should not pay little attention to the culture of the target one as well. The translator should take the context of the target language into account even if he/she aims to construct the culture of the target language. So the translator should be familiar with not only the bilingual pragmatic principles but also bi-cultural communicative knowledge managing to communicate with the pragmatic variations. Moreover, the translation has to be with cultural transferring if the content of translation is the cultural vacancy in the target language by chance. Finally, in fact, the stylistic transferring in culture cannot be ignored.

\section{The Transferring in Style}

In poetry, SU Man-shu uses the natural and fluent Chinese to transmit the translation to Chinese readers with the typical Chinese version.

Example: My love is a red red rose:

Canqubieyumei / ligezaixusou / Ayangzaorigui / wanlimochichu.

SU Man-su's Chinese version is beautiful in diction and serious in cadence. The complexion is very euphemistic as though it is a colloquial Chinese Five-Character poem, although the plain and clear style with a rural and simple figure in the source poem by Burns disappears in Chinese version. In this way, readers in the target language see a portrait of a typical Chinese ancient beauty who is taking a farewell covering her face with her long silk sleeve. The readers in the target language are much satisfied with this cultural transferring in style. The Chinese version makes them comprehend the source poem dynamically in the context of target language. This is with communicative equivalence completely .

Another example is The Elegy by Thomas Gray:

The curfew tolls the knell of parting day / The lowing hard wind slowly o'er the lea / The plowman homeward plods his weary way / Any leaves the world to darkness and to me (YANG, 2006 p. 58).

FENG Hua-zhan's Chinese version is that wanzhongyinyinxiang / xiyangyixichen / qunniuhujiaogui / yuhuizoucaojing / nongfuhechuli / juanjuanhuijiamen (YANG, 2006, p. 58). 
The Elegy by Gray is deep in tone, grave in style, and outstanding in cadence. The poet produces the emotion when in the situation of signing because of mourning. His repressing meditation is speaking tirelessly. Chinese version is slow in rhythm, harmonious in rime, and miraculous in writing. For instance, in "wanzhongyinyinxiang" and "juanjuanhuijiamen", the translator's cultural transferring in style is equally outstanding. "The version expresses fully the high level of artistic conception of the source poem" (YANG, 2006, p. 58). QIAN Zhong-shu interprets the feature and communication of translation from the exegetic content of Origin of Chinese Characters by XU Zhen as lure, media, extorting, and changing among which the extorting is as the Western translators called "The translator is the betrayer". In fact, there are many kinds of betraying in translation among which the translator himself/herself adulterates his/her own understanding and interpreting towards the source work. The translator totally betrays and abandons boldly the writer of the source language as though a woman abandons her husband hard-heatedly pursuing the beautiful infidelity to the source language. Hence the translator with the target language "swallows" or "cannibalizes" the text of source language and culture. Maybe the rough "aggression" to the source language lies in that the translator's responsibility himself/herself works finally (XU, 2003, p. 115). Actually, the translation of cultural transferring is an activity of losing steadiness of the cultural identity, which becomes the foundation of the new cultural model. Culture, in this way, embodies hermeneutic features regardless of spokesman or intellects. Cultural transferring is with the potential subversion to the source language. The cultural transferring in translation is an activity that can make cultural identity lose its stability which can lay the foundation of the new culture. Translation never be transparent according to the the sense of the manipulation in translation. Translation tells readers more about the background of translator but not the background of the work he translates. The literary translation will be controlled by the target language. The creative betraying in mistranslation and omission of translation adapts the situation of the target language. YANG Cheng-wu points out that translation is interpreting which goes through the whole work in which the writer of the source language along with the reader in the target language is responsible for the translation. The representative of hermeneutics assumes that the aim of the hermeneutic activity is to understand the translation of the work more than the source one. In this way, rewriting is an translation phenomenon inevitably.

\section{Questions for Thought}

The first is the cultural vacancy. In translation, from the perspective of context, the cultural vacancy is the obstacle of the translation both from Chinese to English and English to Chinese. In the process of translation, the problem comes to be complicated when emerged with the cultural gap.

Example: kongyijishizhanzhehejiuerchuanchangshandeweiyideren.

In Chinese culture, someone who is wearing long gowned customer before 1949 refers to literate people. "He is drinking standing" refers that he is the poor people. Here LU Xun gives a vivid depiction with sub-language; however, unfortunately some versions fail to note the two items above. The static sub-language is easily misunderstood by the English readers who meet the cultural vacancy accidentally.

If his example is translated like this, it will be better:

KONG Yi-ji was only long-gowned(1) customer who used to drink his wine standing(2). 
Notes: (1) "long-gowned customer" implies the philosopher in Chinese culture;

(2) “...drink his wine standing” hints the poverty-stricken people in Chinese cultural discourse, for if someone is rich, he or she will first reserve and then have a seat according to the reservation.

Secondly, the issue of drama language translation Static language has to be regarded as the leaves if the dancing language is called the flower. The translator or mediator fails to give a communicative version dynamically. In other words, he or she fails to transmit the rhythmic rhyming of the work of the source language if regardless of the static sub-language attached to the dancing one professionally. So the static sub-language is difficult to translate in dancing language, for example, wearing long gown with the dynamic gesturing acting, especially the great actress' or actor's spilling from inside to outside with bearing the ancient Chinese traditional contents hierarchically. They should be taken into account by the translator. If he or she fails to be with the bilingual and bi-cultural lore or fails to be with the multidimensional perspectives culturally, the translator will doom to fail to transfer the rhythmic rhyming of the source culture and language to the target one (YANG, 2006, p. 97).

Finally, it is the non-translation on Chinese ancient poetry (YANG, 2006, p. 13). Because of the historical and social discourse in the ancient time, the modern version of the Chinese ancient poetry is only the decoding of the ancient "information" even though the word had not been invented at the moment. The allegorical poem by one of Chinese famous poets TAO Yuan-ming entitled Flesh, Shadow and Spirit had the hot discussion: Someone thinks that the poem embodies the point of view towards the universe; someone other argues that it is the Confucius' idea; and someone else thinks that it is on the new nature (WANG, 1999, p. 1). The translation of the modern version no matter who translates it is like sort of the distilled water with language information but without cultural content and situation. Any way, any translation of the Chinese ancient poetry to the modern one faces the same issue: if not, no one can know or understand the Ancient Chinese poetry. If, his or her translations will get stuck of the mud of losing the beauty of both the ancient Chinese and the history. So if people want to appreciate the Chinese ancient poetry, he or she has to learn Chinese ancient language in order to analyze and appreciate them well no matter who he or she is, no matter what country he or she comes from, or no matter when or how he or she learns. The only way is to learn beautiful Chinese ancient language and the long and profound Chinese history. In this way people can understand the Chinese poetry right, either is the English ancient poetry.

There are lots of images in Chinese classical poetry. Because poets always live in a certain living environment, images which are the deepening deposit in Chinese culture must reflect certain cultural features in the definite ancient time. They reserve much Chinese national cultural spirits condensing poets' passion chronologically (YANG, 2011, p. 66). So it is difficult for translators to translate the Chinese classical poetry into the modern ones, for he or she does not live in that ancient time. That is the contradiction from which if he or she translates he or she will lose much cultural imagery. If not, modern people will fail to know what the ancient poetry is. Maybe one of solutions to it is to use Image Schema Theory to interpret but not translate only. In this way Image Schema Theory can help the translator to understand its essence, so as to form the right translation principle and choose the appropriate translation strategies (YANG, 2011, p. 70). The modern translation of the Chinese classic poetry solves the problem of Time Difference, however, it loses literariness in translation. It is possible for translators to translate it in modern one for its modern notes but impossible for its 
literariness. The modern translation of Chinese classical poetry gives translator a message that the foreign version of Chinese classic poetry loses the literariness as well. This is worthy of meditation.

\section{Conclusion}

The study of translation has been conversing into the cultural facet which breaks the limitation of the language facet. In this case, the definition of the translation should be transmuted from the language statement to the cultural interpretation. The essential unit of the translation is not a word, a sentence, or even not a text but culture (YANG, 2006, p. 2). Translation is an intercultural transforming. Apart from the proficiency of multilingual lore, the translator should even get the proficiency of intercultural communication. Translation is an intercultural activity which is not only adaptable to the languages in which they share the same culture in some respects such as German and English, but also adapts to the language in which the culture is heathen one such as Finland and Chinese (LIAO, 2001, p. 366). The cultural turning in translation from various languages is not the variation in classification but the differences in the degree. That is Ode to the Difference (WANG, 2004). So translators should pay much more attention to something behind the literary language. ${ }^{1}$

\section{References}

GUI, S. C. (2012). The new view of language and communication. Foreign Language Teaching and Research, 5, 765-774. HE, Q. X. (n.d.). Retrieved from Blog.sina.com.cn/s/blog_486c0f67010081mn.html

HU, J. L. (2003). The detailed notes in the famous English poetry. Beijing: Foreign Language Teaching and Research Press.

HU, W. Z. (1988). The interculturology with English learning. Shanghai: Shanghai Translation Press.

HU, W. Z. (2006). The self-selection on English education. Beijing: Foreign Language Teaching and Research Press.

HU, W. Z. (2012). The outline of interculturology. Beijing: Foreign Language Teaching and Research Press.

Kroeber, A. L., \& Cluckhohm, C. (1952). Culture: A critical review of concepts and definitions. In S. Bassnett and A. Lefevere (Eds.), Constructing cultures. Shanghai: Shanghai Foreign Language Education Press.

LIAO, Q. Y. (2001). The contemporary theory of English translation. In J. XU (Ed.), The theories of foreign translation books. Hubei: Hubei Education Press.

LV, J. (2002). On problems of criteria of translation in postmodernism. Foreign languages and Their Teaching, 3, 41-45.

Nida, E. A. (1993). Language, culture, and translating. Shanghai: Shanghai Foreign Language Education Press.

SUN, Y. Z. (2008). English education and liberal education. Beijing: Foreign Language Teaching and Research Press.

WANG, D. Z. (2004). Ode to the difference. Nanning: Guangxi Normal University Press.

WANG, H. Y. (2003). Critique of translation theories in Chinese (From Dao An to Fu Lei). Wuhan: Hubei educational Press.

WANG, H. Y. (2004). Masterpieces of English poems from Shakespeare to Ginsberg: Translation and commentary. Jinan: Shandong University Press.

WANG, R. P. (1999). A profound allegorical poem. In R. P. WANG (Ed.), The research on college foreign language. Changchun: Changchun Press.

XU, J. (2003). Translation theory. Wuhan: Hubei Educational Press.

YANG, J. F. (2006). The art of translation. Shenyang: Shenyang Press.

YANG, J. F. (2011). Observing the interpreting space in the scheme theory on images from translations of Ancient Chinese poetry. Foreign Languages and Their Teaching, 4, 66-70.

\footnotetext{
${ }^{1}$ See Blog.sina.com.cn/s/blog_486c0f67010081mn.html.
} 